\title{
Determinants of exclusive breastfeeding among mothers of infants aged 6 to 12 months in Gwanda District, Zimbabwe
}

\author{
Paddington T. Mundagowa ${ }^{1 *}$, Elizabeth M. Chadambuka ${ }^{1}$, Pugie T. Chimberengwa ${ }^{2}$ \\ and Fadzai Mukora-Mutseyekwa ${ }^{3}$
}

\begin{abstract}
Background: In 2016, 98\% of children in Zimbabwe received breastmilk, however only 40\% of babies under six months were exclusively breastfed $24 \mathrm{~h}$ prior to data collection. A 2014 survey revealed that Matabeleland South Province had the country's highest starvation rates and food insecurities were rife. This study aimed at investigating maternal, infant, household, environmental and cultural factors influencing exclusive breastfeeding (EBF) practice in Gwanda District.
\end{abstract}

Methods: A cross-sectional study was conducted from January to March 2018. Interviews used pretested structured questionnaires for 225 mothers of infants aged between six and twelve months at immunization outreach points and health facilities. Descriptive statistics, bivariate and multivariate analysis estimated the association between the dependent and independent variables. Exclusive breastfeeding was defined as feeding an infant on breast milk only from birth up to the age of six months.

Results: The majority of mothers ( $n=193 ; 89 \%)$ had knowledge about EBF and 189 (84\%) expressed a positive attitude towards the practice, however, only 81 (36\%) practiced exclusive breastfeeding. The most common complementary food/fluid given to the infants was plain water $(n=85 ; 59 \%)$. Predictors for EBF were: maternal Human Immuno-deficiency Virus positive status (Odds Ratio [OR] 0.30; 95\% Confidence Interval [CI] 0.17, 0.56) and being economically independent (OR $0.41 ; 95 \% \mathrm{Cl} 0.21,0.79)$. Barriers to practicing EBF were: being a young mother under 25 years of age (OR 3.05; 95\% Cl 1.67, 5.57), having one or two children (OR 2.49; 95\% Cl 1.29, 4.79), living in less than two rooms (OR 3.86; $95 \% \mathrm{Cl} 1.88,7.93)$ and having a baby of low birthweight (OR 1.05; 95\% Cl 0.40, 2.71). After multivariate analysis, only the mother's economic independence was associated with practicing EBF (Adjusted OR [AOR] 0.83; 95\% Cl 0.30, 0.92). Key informants identified traditional family practices as the major barrier to EBF.

Conclusion: The exclusive breastfeeding rates were low despite the mothers' high knowledge levels and positive attitudes towards the practice. In addressing the multiple factors influencing the cost effective practice, there is need to channel supportive measures through a system-wide approach. This can be achieved by realigning breastfeeding policy directives as well as community attitudes and values towards the exclusive breastfeeding.

Keywords: Exclusive breastfeeding, Practices, Infant, Maternal, Gwanda

\footnotetext{
* Correspondence: mundagowap@africau.edu

${ }^{1}$ College of Health Agriculture and Natural Sciences, Africa University, Mutare,

Zimbabwe

Full list of author information is available at the end of the article
}

(c) The Author(s). 2019 Open Access This article is distributed under the terms of the Creative Commons Attribution 4.0 International License (http://creativecommons.org/licenses/by/4.0/), which permits unrestricted use, distribution, and reproduction in any medium, provided you give appropriate credit to the original author(s) and the source, provide a link to the Creative Commons license, and indicate if changes were made. The Creative Commons Public Domain Dedication waiver (http://creativecommons.org/publicdomain/zero/1.0/) applies to the data made available in this article, unless otherwise stated. 


\section{Background}

Exclusive breastfeeding (EBF) refers to the practice of feeding an infant on breast milk alone for the first six months of life without addition of other food or water [1]. World Health Organization (WHO) and United Nations International Children's Fund (UNICEF) recommend mothers to initiate breastfeeding within the first hour after birth. Thereafter, mothers should continue feeding their babies with breast milk alone (including expressed milk or from a wet nurse) for at least the first six months of life before addition of complementary feeding. Exclusively breastfed infants can only take oral rehydration solution, vitamins and minerals, and prescribed medications. Scientific studies by WHO and UNICEF have proven that breastfeeding is beneficial to both the child and the mother [2]. Breast milk lowers the baby's risk of sickness from acute and chronic infections and is a cost-effective intervention that reduces infant mortality and morbidity [3, 4].

Many African mothers breastfeed their babies beyond one year but EBF for up to six months is still not commonly practiced [5]. Early introduction of complementary feeding escalates the risk of diarrhea, malnutrition and death [6]. Approximately $22 \%$ of infant deaths could be prevented if mothers practiced EBF [7, 8].

In 2016, national statistics showed that $98 \%$ of children in Zimbabwe were fed on breastmilk however, only $40 \%$ of babies under six months were exclusively breastfed $24 \mathrm{~h}$ prior to data collection [9]. According to the Zimbabwe National Nutrition Survey Report of 2018 which used the definition of exclusive breastfeeding as feeding baby on breastmilk only for the past $24 \mathrm{~h}$ prior to data collection, Matabeleland South had an EBF rate of $71 \%$ [10]. Suboptimal breastfeeding practices in Zimbabwe put most babies at risk of malnutrition [11]. In 2014, Matabeleland South Province had the highest starvation rates in the country and most families survived on one meagre meal per day [12].

In May 2017, the Zimbabwean Ministry of Health and Child Care (MoHCC) carried out a national Lot Quality Assurance Sampling (LQAS) program on nutrition monitoring and Gwanda District was identified as one of the 18 Emergency Districts which were in dire need of infant nutrition monitoring and support [13]. The government and partners such as Global Alliance (GOAL) and UNICEF had versatile Infant and Young Children Feeding (IYCF) programs in the district but provincial median duration for EBF was at 3.7 months instead of six months [14].

This study sought to assess maternal knowledge and attitudes to EBF in Gwanda District. We also sought to determine the maternal and infant related factors as well as household, environmental, psychosocial, cultural factors influencing EBF in the district. Thus, it was pertinent to understand the root causes of the problem by approaching the primary actors in EBF that is, the mothers. We were also motivated to conduct this study in Gwanda District where no similar research has been carried out to date. The urgent need for nutritional support and monitoring in Matabeleland South province prompted the researchers to carry out the study which had the potential to identify factors which encourage or inhibit the uptake of the practice. The significant factors can be used for planning interventions to promote infant nutrition. The study findings could help with the identification of factors which encourage or inhibit the uptake of the practice for planning interventions to promote infant nutrition.

\section{Methods}

\section{Study design}

A community and facility based analytical crosssectional study was conducted to establish the determinants of EBF practices among mothers who had babies aged six to twelve months in Gwanda District. The research study was conducted over a period of eight weeks from January to March 2018.

\section{Study setting and participants}

The study was carried out in Gwanda District, Matabeleland South Province. The district covers areas around Gwanda town which is $126 \mathrm{~km}$ south east of Zimbabwe's second largest city of Bulawayo along the BulawayoBeitbridge highway. The district had 30 health facilities and of these, three were hospitals and 27 were clinics. Gwanda District had an estimated population of 142943 of which 3,971 were children less than one year and 21, 027 children under five years of age. The district had an estimated 32464 women of child bearing age and 5,775 births were expected annually [15].

\section{Sample size and sampling technique}

The sample size was determined using a study on knowledge and attitudes towards EBF in Iran [16] which assumed the standard deviation of 0.36 within the population of EBF mothers. The sample was calculated using the formula $n=\mathrm{Z}^{2} \mathrm{~s}^{2} / \mathrm{e}^{2}$, where $\boldsymbol{n}$ was the sample size, $\mathbf{Z}$ was the test statistic for the $95 \%$ confidence interval [17]. $\mathbf{S}$ was the estimated standard deviation of an attribute that was present in the population (assumed to be 0.36$)$ and e was the desired precision (0.05). After calculation, the minimum sample size for mothers interviewed was approximately 200. A $10 \%$ attrition was anticipated; hence the final adjusted sample size was approximately 223 mothers.

All the 23 health facilities which offer maternal and child health services in the district as well as their respective Extended Program of Immunization Outreach (EPIO) points were selected for the study. Mothers 
recruited from an EPIO point were regarded as participants for a health facility that covers that catchment area. The district had 54 EPIO points and the researchers targeted EPIO days when mothers converged either at the health facility or EPIO points. Eleven Key Informants comprising of nurses, Village Health Workers (VHWs) and nutritionists were purposively selected for the study.

\section{Data collection}

An interviewer administered questionnaire which was translated to the dominant local language IsiNdebele, was used to collect data from the mothers then back to English for consistency. Key informant interview guides were also designed to cater for both English and IsiNdebele speaking participants (nurses, VHWs and nutritionists). The questionnaire for mothers contained some questions adopted from the Iowa Infant Feeding Attitude Scale (IIFAS) [18].

The research instruments were pretested for validity, reliability and clarity at Gwanda Provincial Hospital. Face to face interviews were carried out in a secluded place or private room to promote confidentiality. Researchers continued to visit the clinic or hospital or EPIO point for interviews on immunization days until the sample size specifically calculated for the health facility was reached. Forty-eight (89\%) of the 54 EPIO points as well as two health facilities were visited.

\section{Study variables}

The dependent variable was practicing EBF which refers to feeding the baby on breast milk only from birth up to the age of six months. Mothers who reported correctly practicing EBF were coded 'EBF' whilst those who did not were coded 'non-EBF'. The independent variables for the study were categorized into maternal factors (age, educational level, marital status, health status, knowledge and attitude on EBF, parity, occupation, mode of delivery, HIV status), infant factors (age, health status, sex, birthweight, HIV status), household factors (income source, residence, housing conditions), environmental factors (exposure to media, place of delivery, access to health information), psychosocial and cultural factors (beliefs, religion, self-efficacy).

Mothers with infants 6-12 months of age visiting EPIO points and health facilities during the period of the study were approached for interviews. A written consent form was issued to mothers who met the inclusion criteria and only those who consented to participate in the study were interviewed. Caregivers who were not the mother of the baby and mothers who refused to consent for interviews were also excluded from the study.

\section{Data analysis}

The collected quantitative data were entered and cleaned using Epi Info version 7 before analysis whilst qualitative data was collected from the key informants through use of open-ended questions in the interviewing tool used. The qualitative data obtained were analyzed according to major themes raised during the interviews. Frequencies, means and percentages were used to describe maternal and infant demographic characteristics, knowledge and attitudes on EBF. In measuring maternal knowledge, a correct response was awarded a score of one and an incorrect answer a zero out of a total score of five.

Descriptive statistics, bivariate and multivariate analysis were done in order to ascertain the association between the dependent and independent variables. Multivariate analysis was carried out to measure the strength of interrelationships of several variables at once. Variables such as maternal age, marital status, mode of delivery were inputted simultaneously and compared. A resulting $p$ - value of less than 0.05 was considered to be statistically significant.

\section{Results}

\section{Sociodemographic characteristics}

Table 1 shows the maternal sociodemographic characteristics for mothers who participated in the study. The mean age was $26 \pm 6$ years and $67 \%$ of the study participants were in the age group $20-30$ years and $64 \%$ did not practice EBF. Most mothers were married and had one or two children. The majority were educated to secondary school level, were unemployed and resided in rural areas. Partners/husbands were the major income source in nearly three quarters of the study sample and more than half of the women gave their infants plain water before the age of six months. The majority (99.6\%) of the participants in this study fed their babies on breastmilk but the EBF rate was low (36\%).

\section{Maternal knowledge and attitudes on EBF}

The majority of women (89\%) had knowledge of what exclusive breastfeeding is by definition. Scores on a Likert scale revealed that all interviewed women agreed that breast milk should be the first feed to be given to the baby soon after birth. Ninety-five percent $(n=213)$ agreed that the baby should be put to the breast within an hour of birth and $98 \%$ cited that exclusive breastfeeding protects the baby from illnesses. However, 77\% ( $n=$ $111)$ of those who did not practice EBF and $79 \%(n=64)$ of those who practiced EBF their infants disagreed to continuing with breastfeeding when a mother is pregnant.

On an attitude scale (IIFAS), almost all study participants $(99 \%)$ scored high with regard to EBF being more convenient and beneficial to the baby when compared to 
Table 1 Maternal sociodemographic characteristics in Gwanda District, Matabeleland South Province, 2018. ( N=225)

\begin{tabular}{|c|c|c|c|c|c|c|c|}
\hline \multirow[t]{2}{*}{ Variable } & \multirow[t]{2}{*}{ Category } & \multicolumn{2}{|c|}{${ }^{a}$ Non-EBF } & \multicolumn{2}{|l|}{ EBF } & \multicolumn{2}{|l|}{ Total } \\
\hline & & $n=144$ & $\%$ & $n=81$ & $\%$ & $n=225$ & $\%$ \\
\hline \multirow[t]{4}{*}{ Age (years) } & $<20$ & 6 & 75 & 2 & 25 & 8 & 4 \\
\hline & $20-<30$ & 96 & 64 & 55 & 36 & 151 & 66 \\
\hline & $30-<40$ & 28 & 49 & 29 & 51 & 57 & 25 \\
\hline & $40-<50$ & 6 & 67 & 3 & 33 & 9 & 5 \\
\hline \multicolumn{8}{|c|}{ Median age $=26 \pm 6$ years } \\
\hline \multirow[t]{4}{*}{ Marital status } & Married & 103 & 65 & 55 & 35 & 158 & 70 \\
\hline & Cohabiting & 17 & 65 & 55 & 35 & 158 & 70 \\
\hline & Single & 13 & 54 & 11 & 46 & 24 & 10 \\
\hline & Separated/divorced & 9 & 53 & 8 & 47 & 17 & 8 \\
\hline \multirow[t]{3}{*}{ Parity } & 1-2 children & 101 & 66 & 52 & 34 & 153 & 68 \\
\hline & 3-4 children & 37 & 61 & 24 & 39 & 61 & 27 \\
\hline & $>4$ children & 6 & 55 & 5 & 45 & 11 & 5 \\
\hline \multirow[t]{4}{*}{ Education level } & No formal education & 2 & 100 & 0 & 0 & 2 & 1 \\
\hline & Primary & 22 & 54 & 19 & 46 & 41 & 18 \\
\hline & Secondary & 118 & 70 & 51 & 30 & 169 & 75 \\
\hline & Tertiary & 2 & 15 & 11 & 80 & 13 & 6 \\
\hline \multirow[t]{3}{*}{ Occupation } & Unemployed & 117 & 66 & 61 & 34 & 178 & 79 \\
\hline & Formal & 9 & 50 & 9 & 50 & 18 & 8 \\
\hline & Self employed & 18 & 62 & 11 & 38 & 29 & 13 \\
\hline \multirow[t]{5}{*}{ Religion } & Apostolic & 67 & 71 & 28 & 29 & 95 & 42 \\
\hline & Pentecostal & 40 & 63 & 24 & 37 & 64 & 29 \\
\hline & Protestant & 19 & 49 & 20 & 51 & 39 & 17 \\
\hline & None & 12 & 57 & 9 & 43 & 21 & 9 \\
\hline & Catholic & 6 & 100 & 0 & 0 & 6 & 3 \\
\hline \multirow[t]{3}{*}{ Residence } & Rural & 96 & 62 & 58 & 38 & 154 & 68 \\
\hline & Urban & 26 & 59 & 18 & 41 & 44 & 20 \\
\hline & Mine/farm & 22 & 81 & 5 & 19 & 27 & 12 \\
\hline \multirow[t]{3}{*}{ Number of rooms } & $1-2$ & 90 & 76 & 29 & 24 & 119 & 53 \\
\hline & $3-4$ & 42 & 53 & 38 & 47 & 80 & 36 \\
\hline & $>4$ & 11 & 44 & 14 & 56 & 25 & 11 \\
\hline \multirow[t]{3}{*}{ Income source } & Partner/husband & 113 & 69 & 51 & 31 & 164 & 73 \\
\hline & Self-employed & 41 & 46 & 24 & 53 & 45 & 20 \\
\hline & Relatives & 10 & 63 & 6 & 37 & 16 & 7 \\
\hline
\end{tabular}

${ }^{a}$ Non-EBF Did not practice Exclusive Breastfeeding

formula/mixed feeding. Approximately 90\% $(n=202)$ of the women either agreed or strongly agreed that the age of the mother does not influence her ability to practice exclusive breastfeeding. On EBF being the best choice for working mothers, $33 \%(n=48)$ of those who did not practice EBF, disagreed when compared to $10 \%(n=8)$ of those who practiced EBF and disagreed. Ninety-five percent of the interviewed women either agreed or strongly agreed that breastfed babies are healthier than formula/mixed fed babies. Using the IIFAS, mothers who practiced EBF had a more positive attitude level $(n=68 ; 84 \%)$ when compared to mothers who did not.

The Table 2 shows that being a young mother, having one or two children and having a baby of low birthweight was significantly associated with failure to practice whilst mothers with a positive HIV status were more likely to practice EBF.

Table 3 shows that economically independent women were more likely to breastfeed their babies on breast milk only up to the age of six months whilst those who 
Table 2 Sociodemographic and health related factors influencing EBF in Gwanda District, Matabeleland South Province, $2018(N=225)$

\begin{tabular}{lllll}
\hline Variable & Non-EBF & EBF & OR $(95 \% \mathrm{Cl})$ & $p$-value \\
& $n=144$ & $n=81$ & &
\end{tabular}

Age: Young mother (less than 25 years old)

$\begin{array}{lllll}\text { Yes } & 72 & 20 & 1 & \\ \text { No } & 72 & 61 & 3.05(1.67,5.57) & 0.0002\end{array}$

Marital status: Live with partner

$\begin{array}{lllll}\text { Yes } & 120 & 64 & 1 & \\ \text { No } & 22 & 19 & 0.62(0.31,1.22) & 0.17\end{array}$

Parity: Had 1 or 2 children

$\begin{array}{lllll}\text { Yes } & 52 & 15 & 1 & \\ \text { No } & 92 & 66 & 2.49(1.29,4.79) & 0.006\end{array}$

Attended formal education

$\begin{array}{lllll}\text { No } & 24 & 19 & 1 & \\ \text { Yes } & 120 & 62 & 0.65(0.33,1.28) & 0.21\end{array}$

Maternal HIV status

$\begin{array}{lllll}\text { Positive } & 27 & 35 & 1 & \\ \text { Negative } & 117 & 46 & 0.30(0.17,0.56) & 0.0001\end{array}$

Had a chronic disease/condition

$\begin{array}{lllll}\text { Yes } & 8 & 9 & 1 & \\ \text { No } & 136 & 72 & 0.47(0.17,1.30) & 0.13\end{array}$

Low birthweight (Below $2500 \mathrm{~g}$ )

$\begin{array}{lllll}\text { Yes } & 13 & 7 & 1 & \\ \text { No } & 131 & 74 & 1.05(0.40,2.71) & 0.01\end{array}$

Large birthweight (Above $3500 \mathrm{~g}$ )

$\begin{array}{lllll}\text { Yes } & 31 & 24 & 1 & \\ \text { No } & 113 & 57 & 0.65(0.35,1.21) & 0.17\end{array}$

Sex of the baby

$\begin{array}{lllll}\text { Boy } & 81 & 40 & 1 & \\ \text { Girl } & 63 & 41 & 0.76(0.44,1.31) & 0.32\end{array}$

Baby sick for more than 2 weeks when he/she was under 6 months of age

$\begin{array}{lllll}\text { Yes } & 27 & 13 & 1 & \\ \text { No } & 117 & 68 & 1.21(0.58,2.49) & 0.61\end{array}$

Infant's HIV Status

$\begin{array}{lllll}\text { Positive } & 2^{\mathrm{a}} & 0^{\mathrm{a}} & 1 & \\ \text { Negative } & 142 & 81 & 0.00 & 0.00\end{array}$

OR Odds Ratio, $\mathrm{Cl}$ Confidence Interval, Chi-square test of association was used to obtain $p$ - values and Odds ratios

${ }^{\text {a }}$ Cell count is $<5$, Chi-square test may not be valid

lived in one or two rooms were less likely to practice EBF. Obstetrics and sociocultural factors influencing EBF practice were found not to be significantly associated with the practice as indicated in Table 4. After multivariate analysis, only the mother's economic independence was associated with practicing EBF (AOR 0.83; 95\% CI 0.30, 0.92; $p<0.001$ ).
Table 3 Household and environmental factors influencing EBF Practices in Gwanda District, Matabeleland South Province, 2018

\begin{tabular}{|c|c|c|c|c|}
\hline Variable & $\begin{array}{l}\text { Non-EBF } \\
n=144\end{array}$ & $\begin{array}{l}\text { EBF } \\
n=81\end{array}$ & OR $(95 \% \mathrm{Cl})$ & $p$-value \\
\hline \multicolumn{5}{|c|}{ Maternal occupation } \\
\hline Employed & 27 & 20 & 1 & \\
\hline Unemployed & 117 & 61 & $1.42(0.73,2.74)$ & 0.29 \\
\hline \multicolumn{5}{|l|}{ Income source } \\
\hline Independent & 21 & 24 & 1 & \\
\hline Dependent & 123 & 57 & $0.41(0.21,0.79)$ & 0.007 \\
\hline \multicolumn{5}{|l|}{ Residence } \\
\hline Rural & 96 & 58 & 1 & \\
\hline Urban/mine & 48 & 23 & $0.73(0.44,1.44)$ & 0.45 \\
\hline \multicolumn{5}{|c|}{ Live in few rooms ( 1 or 2 ) } \\
\hline Yes & 54 & 11 & 1 & \\
\hline No & 89 & 70 & $3.86(1.88,7.93)$ & 0.0001 \\
\hline
\end{tabular}

Chi-square test of association was used to obtain $p$ - values and Odds ratios

Table 4 Obstetric and sociocultural factors influencing EBF in Gwanda District, Matabeleland South Province, 2018 ( $N=225)$

\begin{tabular}{lllll}
\hline Variable & $\begin{array}{l}\text { Non-EBF } \\
n=144\end{array}$ & $\begin{array}{l}\mathrm{EBF} \\
n=81\end{array}$ & OR $(95 \% \mathrm{Cl})$ & $p$-value \\
\hline $\begin{array}{lllll}\text { Place of birth: } \\
\text { Home }\end{array}$ & $2^{\mathrm{a}}$ & 5 & 1 & \\
$\begin{array}{l}\text { Health facility } \\
\text { Mode of delivery }\end{array}$ & 142 & 76 & $0.21(0.04,1.12)$ & 0.05 \\
$\begin{array}{l}\text { Cesarean } \\
\text { Vaginal/assisted }\end{array}$ & 19 & 15 & 1 & \\
& 124 & 66 & $0.67(0.32,1.41)$ & 0.29
\end{tabular}

Baby breastfed in the first hour of birth

$\begin{array}{lllll}\text { No } & 64 & 26 & 1 & \\ \text { Yes } & 83 & 56 & 1.66(0.94,2.93) & 0.08\end{array}$

Visited Antenatal Clinic

$\begin{array}{lllll}\text { No } & 7 & 3^{\mathrm{a}} & 1 & \\ \text { Yes } & 137 & 78 & 0.75(0.19,3.00) & 0.69 \\ \text { Religion } & & & & \\ \text { Apostolic } & 67 & 28 & 1 & \\ \text { Other } & 77 & 53 & 1.65(0.94,2.90) & 0.08\end{array}$

Treated depressed fontanel using traditional remedies (inkanda)

$$
\begin{array}{lllll}
\text { Yes } & 70 & 29 & 1 & \\
\text { No } & 74 & 52 & 1.70(0.97,2.97) & 0.06
\end{array}
$$

\begin{tabular}{|c|c|c|c|c|}
\hline Yes & 14 & 5 & 1 & \\
\hline No & 130 & 76 & $1.64(0.57,4.72)$ & 0.36 \\
\hline
\end{tabular}

Any breastfeeding problems up to 6 months 


\section{Discussion}

The aim of this study was to assess the knowledge and attitudes on exclusive breastfeeding in Gwanda District. We also sought to determine the different maternal, infant, household, environmental, psychosocial and cultural factors influencing EBF practice in this district.

The majority (99.6\%) of the participants in this study fed their babies on breastmilk although the EBF rate was low (36\%). This EBF rate was lower than the national EBF rate $(40 \%)$ reported in the Multiple Indicator Cluster Survey (MICS) findings of 2014 and provincial rate reported in the Zimbabwe National Nutrition Survey of 2018 (71\%) [10]. The lower estimates of EBF observed in this study were due to the differences in the definitions of EBF since the national surveys used $24 \mathrm{~h}$ reporting period rather than the birth to six months period used in this study. The EBF rate we found was higher than studies in Ethiopia (26.4\%) and Brazil (15.2\%) [19, 20]. Variations in sociodemographic characteristics and cross-cultural preferences may be the cause of differences in the EBF rates.

The interviewed women were knowledgeable on EBF practices, despite the low EBF rate in the Gwanda community. This finding was similar to a study in Nigeria were knowledge was high (82\%) but the EBF rate was low (33.5\%) [21]. This finding explains why having the knowledge of EBF does not necessarily translates to EBF practice. In most cases, social pressure to introduce complementary feeds tends to outweigh the mother's knowledge of EBF benefits [22].

Mothers who had one or two children were less likely to exclusively breastfeed their babies when compared to mothers with three or more children. This finding was consistent with study findings in a Jordan study were they concluded that multi-parity was a major predictor of exclusive breastfeeding [23]. Being a novice mother was also found out to be a threat to EBF in two studies conducted in Brazil [20, 24]. The increase in maternal confidence with several prior pregnancies could be due to previous positive experiences in breastfeeding as well as previous negative outcomes observed with early introduction of complementary foods.

Young mothers (less than 25 years of age) were less likely to practice of exclusive breastfeeding in Gwanda District. This finding was similar to observations in a Chinese study were mothers of the age group 15-24 years were less likely to practice EBF due to general traditional practice of prelacteal feeding especially in rural areas [25]. Similarly, a Brazilian study concluded that adolescent mothers were less likely to EBF when compared with older mothers [26]. Being an older mother comes with previous experience, added conviction and commitment to motherhood hence an increased likelihood to EBF the infant [27].
Women who lived in fewer rooms (one or two) were less likely to practice exclusive breastfeeding when compared to those who had and used more than three rooms. Living in fewer rooms can limit the mother's privacy. Some African cultures view the female breast as a part of a women's identity and femininity which must remain private, and it is a taboo to expose one's breasts or openly talk about the breasts [28]. Thus, breastfeeding in the presence of the in-laws or any other respected elders can be viewed as contemptuous behavior. Thus, mothers may not be able to frequently breastfeed in the presence of in-laws or elders due to the limited privacy.

Mothers who were financially independent were more likely to exclusively breastfeed their babies in Gwanda District (OR 0.4; 95\% CI 0.21, 0.79; $p=0.007$ ). This finding was contrary to studies in which EBF rates were lower among employed mothers when compared to unemployed dependent mothers [19, 29]. Dependence limits the mother's sense of autonomy. Dependent women often adhere to family opinions on infant feeding because their in-laws or partners dictate what can be given to the baby thus, it is difficult for them to adhere to EBF principles [30].

A maternal HIV positive status was found to be significantly associated with the practice of EBF in Gwanda District. This finding was consistent with studies in South Africa in which they identified that HIV positive women had more knowledge on EBF and were more likely to EBF their babies [31-33]. Mothers who knew their positive HIV status revealed urgency in preventing transmission of the virus to the baby, hence EBF uptake was high among HIV positive mothers [34].

The latest WHO guidelines recommend that health workers encourage EBF to HIV positive mothers [2]. The encouraging uptake or the EBF practice by seropositive mothers shows that the education given to pregnant women by health workers in Gwanda District was consistent with the WHO guidelines. Exclusive breastfeeding by HIV positive women had the potential to reduce mother to child transmission of HIV in Gwanda District.

Babies who had low birthweight (below $2500 \mathrm{~g}$ ) were $4 \%$ less likely to be EBF when compared to babies who had a normal birthweight. This was consistent with a South African study results in which they cited the maternal desire for the infant to gain weight prompting mother's decision to add complementary feeding before the age of six months [35]. The percentage of children who were given plain water before the age of six months was $58 \%$ which is significantly higher than the $28 \%$ cited by Zimbabwe Demographic Health Survey (ZDHS 2015) [14]. Our finding was consistent with a study in Binga, Zimbabwe, were mothers gave their young babies plain water with the belief that water would not affect the practice of exclusive breastfeeding [36]. 
When approaching EBF related issues, health workers need to take into consideration all the perceived threats, barriers and benefits associated with the complex decision to EBF for six months. Such an approach has the potential of improving maternal and infant wellbeing in Gwanda District and other similar settings.

\section{Study strengths and limitations}

By collecting data from mothers with infants who were 6 to 12 months of age, the researchers reduced recall bias. Collecting data from both facilities and the community resulted in more representative data and the use of trained as well as experienced research assistants helped in preserving the quality of the obtained data whilst ensuring proper ethical standards are followed.

The findings of this study cannot be generalized for Matabeleland South Province as well as other settings because participants were only drawn from Gwanda District. The use of convenience sampling method interfered with the representativeness of the collected data and self-reporting may have introduced recall bias to the study. The study was also vulnerable to social desirability bias in which some mothers may have felt EBF to be a more socially acceptable hence, felt compelled to respond positively towards EBF practices. Using the crosssectional research design made it challenging for the researchers to establish causality. The omission of nutritional status of children (HAZ- stunting, WHZ- wasting and WAZ- underweight) and mothers' body mass index (BMI) as study variables also limited analysis of the study results.

\section{Conclusion}

The exclusive breastfeeding rates were low despite the mothers' high knowledge levels and positive attitudes towards the practice. In addressing the multiple factors influencing the cost effective practice, there is need to channel supportive measures through a system wide approach. This can be achieved by realigning breastfeeding policy directives as well as community attitudes and values towards the exclusive breastfeeding. Collaborated efforts from both the healthcare sector and society are vital in promoting and sustaining the optimal breastfeeding practice. This has the potential to improve child health and reducing infant morbidity and mortality in Gwanda District.

\section{Abbreviations}

Cl: Confidence Interval; EBF: Exclusive Breastfeeding; EPIO: Extended Program of Immunization Outreach; GOAL: Global Alliance; HIV: Human Immunodeficiency Virus; IIFAS: lowa Infant Feeding Attitude Scale; IYCF: Infant and Young Child Feeding; LQAS: Lot Quality Assurance Sampling; MICS: Multiple Indicator Cluster Survey; MoHCC: Ministry of Health and Child Care; OR: Odds Ratio; UNICEF: United Nations International Children's Fund; VHWs: Village Health Workers; WHO: World Health Organization; ZDHS: Zimbabwe Demographic Health Survey

\section{Acknowledgements}

We would like thank The Provincial Medical Director of Matabeleland South Province for permission to undertake this study. We are also thankful to Gwanda District staff members and mothers for their participation in the study.

\section{Authors' contributions}

PTM came up with the concept, wrote the protocol, collected data and wrote the manuscript. PTC, EMC and FMM reviewed the protocol and the manuscript. All authors read and approved the final manuscript.

\section{Funding}

This research did not receive any specific grant from funding agencies in the public, commercial, or not-for-profit sectors.

\section{Availability of data and materials}

The datasets used and/or analyzed during the current study are available from the corresponding author on reasonable request.

Ethics approval and consent to participate Permission to carry out this study was sought from Africa University Research Ethics Committee (Approval Number: 315/17. Date of approval: 20/12/17) as well as The Provincial Medical Director of Matabeleland South Province.

\section{Consent for publication}

Not applicable.

\section{Competing interests}

The authors declare that they have no competing interests.

\section{Author details}

${ }^{1}$ College of Health Agriculture and Natural Sciences, Africa University, Mutare, Zimbabwe. ${ }^{2}$ Ministry of Health and Child Care, Gwanda Provincial Hospital, Gwanda, Zimbabwe. ${ }^{3}$ Africa University Clinical Research Centre, $132 \mathrm{H}$. Chitepo Street, Mutare, Zimbabwe.

Received: 9 September 2018 Accepted: 30 June 2019

Published online: 09 July 2019

\section{References}

1. Horta BL, Victoria CG. Long-term effects of breastfeeding: a systematic review: World Health Organization; 2014. Retrieved from: https://www. google.com/search?client=firefox-b-d\&q=Horta+BL\%2C+Victoria+CG.+Longterm+effects+of+breastfeeding\%3A+a+systematic+review.+World+Health+ Organization.+2014. Accessed 17 Dec 2017.

2. UNICEF. UNICEF-Nutrition-Breastfeeding. Retrieved from https://www.unicef. org/nutrition/index_24824.html. Accessed 27 August 2017 (2017).

3. UNICEF. Tracking progress on child and maternal nutrition: a survival development priority: UNICEF. Accessed from https://www.unicef.org/ publications/index 51656.html. Accessed 17 Dec 2017; 2009.

4. Rajeshwari K, Bang A, Chaturvedi P, Kumar V, Yadav B, Bharadva K, et al. Infant and young child feeding guidelines: 2010. Indian Pediatr. 2010;47(12): 995-1004.

5. Black RE, Victoria CG, Walker SP, Christian P, De Onis M, Ezzati M. Maternal and child undernutrition and overweight in low-income and middleincome countries. Lancet. 2013;382(9890):427-51.

6. World Health Organization. The 2012 World Breastfeeding Conference Declaration and Call for Action. New Delhi: Presented at the 2012 world breastfeeding conference; 2012.

7. Mason F, Rawe K, Wright S. Superfood for babies: how overcoming barriers to breastfeeding will save children's lives. London: The Save the Children Fund; 2013

8. Joshi PC, Angdembe MR, Das SK, Ahmed S, Faruque ASG, Ahmed T. Prevalence of exclusive breastfeeding and associated factors among mothers in rural Bangladesh: a cross sectional study. Int Breastfeed J. 2014;9:7.

9. UNICEF Zimbabwe. Extended Analysis of Multiple Indicator Cluster Survey (MICS) 2014: A story of inequality and inequity in Zimbabwe. Nutrition, health and water and sanitation. Harare: Zimbabwe National Statistics Agency; 2016 
10. UNICEF Zimbabwe. Zimbabwe National Nutrition Survey 2018. Available at: https://www.unicef.org/zimbabwe/reports/zimbabwe-2018-nationalnutrition-survey-report Accessed: 22 Nov 2018.

11. Zimbabwe Ministry of Health and Child Care. The National Health Strategy for Zimbabwe 2016-2020; 2016.

12. Moyo F. Kwashiorkor rife in Matabeleland South Province. 2014, The Chronicle Newspaper, Accessed: 11 Aug 2017.

13. Ministry of Health and Child Care. Report on nutrition monitoring in 18 emergency districts using lot quality assurance sampling. 2017.

14. Zimbabwe National Statistics Agency and ICF International. Zimbabwe demographic and health survey 2015: key indicators. Rockville: Zimbabwe National Statistics Agency (ZIMSTAT) and ICF International; 2016.

15. Ministry of Health and Child Care, Zimbabwe. Matabeleland South Province Generic Report. Gwanda: Ministry of Health and Child Care of Zimbabwe; 2017.

16. Haghighi M, Varzande R. Maternal knowledge and attitude toward exclusive breastfeeding in six months after birth in shiraz, Iran. Int J Pediatr. 2016; 4(11):3759-67.

17. Daniels WW. Biostatistics: A foundation for Analysis in the Health Sciences. 7th ed. New York: Wiley; 1999.

18. Chen S, Binns C, Liu Y, Maycock B, Zhao Y, Tang L. Attitudes towards breastfeeding-the lowa infant feeding attitude scale in Chinese mothers living in China and Australia. Asia Pac J Clin Nutr. 2013;22(2):266-9.

19. Taddelle M, Fentahun N. Exclusive breastfeeding and maternal employment in Ethiopia: a comparative cross-sectional study. Int J Nutr Food Sci. 2014; 312(3):497-503.

20. Moraes de Olivera M, Camelo SJ. Gestational, perinatal and postnatal factors that interfere with practice of exclusive breastfeeding by 6 months after birth. Int Breastfeed J. 2017;12(1):42.

21. Onah S, Jonathan DJ, Ebenebe J, Ezechukwu C, Ekwochi U, Ndukwu I. Infant feeding practices and maternal socio-demographic factors that influence practice of exclusive breastfeeding among mothers in Nnewi south-East Nigeria: a cross-sectional and analytical study. Int Breastfeed J. 2014;9:6.

22. Leshabari SC, Konil-Booer P, Stram ANA, Poali MM, Moland KM. Translating global recommendations on HIV and infant feeding to the local context: the development of cultural sensitive counseling tools in the Kilimanjaro region, Tanzania. Implement Sci. 2006;1:22.

23. Khasawneh $\mathbf{W}$, Khasawneh AA. Predictors and barriers of breastfeeding in north of Jordan: could we be better? Int Breastfeed J. 2017;12:49.

24. Gigante DP, Victoria CG, Barros FC. Maternal nutrition and duration of breastfeeding in a cohort in Pelotas, Brazil. Rev Saude Publica. 2000;34(3): 259-65.

25. Qiu L, Zhao Y, Binns CW, Lee AH, Xie X. Initiation of breastfeeding and prevalence of exclusive breastfeeding at hospital discharge, sub-urban and rural area of Zhejiang, China. Int Breastfeed J. 2009;4:1.

26. Dias de Oliveira L, Giugliani ERJ, Espirito Santo LC, Nunes LM. Counselling sessions increased duration of exclusive breastfeeding: a randomized clinical trial with adolescent mothers and grandmothers Nutr J. 2014;13:73

27. Avery A, Zimmermann K, Underwood PW, Magnus JH. Confident commitment is key factor for sustained breastfeeding. Birth. 2009;36: $141-8$.

28. Jones DP. Cultural views of the female breast. ABNF. 2004;15(1):15-21.

29. Chekol DA, Biks GA, Gelaw YA, Melsew YA. Exclusive breastfeeding and mothers' employment status in Gondar town, Northwest Ethiopia: a comparative cross-sectional study. Int Breastfeed J. 2017;12:27.

30. Musa S, Muktar HM, Abdulkadir I. Determinants of infant feeding options among HIV infected women in a PMTCT setting in Zaria. Abuth: Nazara Treatment and Care Center; 2009.

31. Mnyani CN, Tait CL, Armstrong J, Blaauw D, Chersich MF, Buchmann EJ, et al. Infant feeding knowledge, perceptions and practices among women with and without HIV in Johannesburg, South Africa; a survey in health care facilities. Int Breastfeed J. 2017;12(1):17.

32. Mphego Z, Madiba S, Ntuli-Ngcobo B. The influence of the family on adherence to exclusive breastfeeding: experiences of prevention of mother to child transmission of HIV for women living in extended family households in poor communities of Mpumalanga Province, South Africa. Afr J Phys Health Educ Recreat Dance. 2014;20(1):279-90.

33. Jama NA, Wilford A, Masango Z, Haskins L, Coutsoudis A, Spies L, et al. Enablers and barriers to success among mothers planning to exclusively breastfeed for 6 months: a qualitative prospective cohort study in Kwazulu Natal, South Africa. Int Breastfeed J. 2017;12:43.

34. Gottlieb D, Shetty AK, Mupfungautsi RM, Bassett MT, Maldonado Y, Katzenstein DA. Infant feeding practices of HIV infected women in Zimbabwe. AIDS Patient Care STDs. 2004;18(1):45-53.

35. Hunter-Adams J, Myer $\mathrm{L}$, Rother H. Perceptions related to breastfeeding and early introduction of complementary foods amongst migrants in Cape Town, South Africa. Int Breastfeed J. 2016;11:29.

36. Maclaine A. Infant feeding practices in Binga and Nyaminyami, Zimbabwe, in relation to HIV. Harare: Save the Children (UK); 2006

\section{Publisher's Note}

Springer Nature remains neutral with regard to jurisdictional claims in published maps and institutional affiliations.
Ready to submit your research? Choose BMC and benefit from:

- fast, convenient online submission

- thorough peer review by experienced researchers in your field

- rapid publication on acceptance

- support for research data, including large and complex data types

- gold Open Access which fosters wider collaboration and increased citations

- maximum visibility for your research: over $100 \mathrm{M}$ website views per year

At $\mathrm{BMC}$, research is always in progress.

Learn more biomedcentral.com/submissions 